\title{
Mothers' satisfaction with a home based early intervention program for children with ASD
}

Authors: Sylvia Rodger ${ }^{1}$, Deb Keen ${ }^{2}$, Michelle Braithwaite ${ }^{3}, \&{\text { Shannon } \text { Cook }^{1}}^{1}$

${ }^{1}$ Corresponding Author:

Sylvia Rodger

Division of Occupational Therapy

School of Health and Rehabilitation Sciences

The University of Queensland

Brisbane, Queensland 4072.

Australia.

Email: s.rodger@uq.edu.au

Phone: 61733651664

Fax: 62733652652

${ }^{2}$ Griffith University

Brisbane, Queensland 4111.

Australia.

${ }^{3}$ School of Education

The University of Queensland

Brisbane, Queensland 4072.

Australia.

${ }^{1}$ School of Health and Rehabilitation Sciences

The University of Queensland

Brisbane, Queensland 4072.

Australia.

Journal of Applied Research in Intellectual Disabilities

Running head for publication: Mothers' satisfaction with early intervention. 


\begin{abstract}
Background:

Early intervention services adopting a family-centred approach are considered important for ensuring parent satisfaction. This study investigated the satisfaction of two mothers with an early intervention program for young children with Autistic Spectrum Disorder.
\end{abstract}

Materials and Methods:

While sixteen mother-child dyads participated in a larger study, two mothers who reported considerably lower satisfaction with the program than the rest of the mothers were the focus of this paper. Using descriptive case studies, various child, parent and service delivery factors that may have influenced satisfaction are described.

Results:

Child and parent factors that may have lessened satisfaction for these two mothers included the child's lack of improvement, child's goal performance post-intervention, parenting stress, and decreased parenting competence. Both mothers also had decreased perceptions of the familycentredness of the service and expressed difficulties with establishing collaborative partnerships.

\title{
Conclusion:
}

This paper proposes that parental satisfaction may be influenced by numerous factors relating to the child, parent, and service. Relationships with service providers appear to be particularly important. 
Keywords: early intervention, family-centred practice, parent satisfaction. 


\section{Introduction}

Autistic Spectrum Disorders (ASD) are pervasive developmental disorders with onset prior to 3 years and characterised by delays in communication, social interaction, and restricted patterns of behaviours (Wing, 1996). Early diagnosis is important for timely access to valuable early intervention services for children and their families. Early intervention is needed because early deficits may be cumulative, hindering later social and communicative functioning (Hwang \& Hughes, 2000). In addition early intervention also helps parents cope with the possible frustration and challenges of parenting a child with ASD (Rogers, 1998). Interventions that are family-centred acknowledge parents as the experts regarding their own children (de Geeter et al. 2002; Mahoney et al. 1998; Rosenbaum et al. 1998). "Family-centred services" also incorporate parental goals and concerns into treatment plans (King et al. 1998). The increasing shift from child-focused, expert-driven, to family-centred services has led professionals to recognise the importance of collaboration as an important component of best practice (Johnson, 2000; Minke \& Scott, 1995; Sperry et al. 1999). Increased parent involvement in early intervention services has led professionals to seek information about parent satisfaction with the services they provide, as a means of improving service delivery through quality assurance processes.

Satisfaction refers to the degree to which parents feel that a service meets their needs and those of their child. Measuring parental satisfaction has four main purposes: (1) to give parents more control over decision-making for their child, (2) to evaluate and further develop services, (3) to increase parents' participation and involvement in evaluative decision-making, and (4) to demonstrate the effectiveness of services (McNaughton, 1994). To date, there has been limited research measuring parents' satisfaction with early intervention programs, particularly for children with ASD. 
A few studies have reported high levels of parent satisfaction with family centred early intervention services (Caro \& Derevensky, 1991). One study that examined the satisfaction of 584 European parents from 27 early intervention services concluded that "parents are in general satisfied with early intervention programs" (Lanners \& Mombaerts, 2000, p. 67). However, data were not collected on aspects of the service delivery, parent or child outcomes. Therefore, researchers were unable to determine why some parents were less satisfied (Lanners \& Mambaerts, 2000). Iversen et al. (2003) studied the satisfaction of 18 parents with three early intervention services. While $87 \%$ of parents reported high levels of satisfaction; it is unknown whether children with ASD were included in these services.

There is little clarity regarding factors that affect parent satisfaction (King et al. 2001) and studies of correlations between child outcomes and parent reported satisfaction are inconclusive. One study reported a low correlation $(r=0.20, p<0.05)$ between child progress and parent satisfaction (Marfo et al. 1991), while another (Upshur, 1991) found no correlation between mothers' satisfaction and child progress. Generalisation of results can not be made as the early intervention was not ASD specific and parents were predominantly of a high socioeconomic status (Upshur, 1991). King et al. (2001) called for longitudinal studies to understand the effects of service outcomes on parental satisfaction. The relationship between satisfaction and parent factors such as stress is unclear, although satisfaction with services is believed to improve parental well-being and decrease feelings of distress and depression (King et al. 2001; Rosenbaum et al. 1998).

Law et al. (2003) reported that the service provider's behaviour is likely to influence parent satisfaction. In order to be family-centred, professionals need to be respectful, supportive, positive, sensitive, friendly, responsive, and knowledgeable about the child's skills as well as community services (King et al. 1995; McWilliam et al. 1998). Open communication is also 
essential to the formation of supportive partnerships (Turnbull \& Turnbull,1986).Communication and the provision of information regarding their child and service options, are strongly associated with parent satisfaction (Law et al. 2003).

The current study aimed to identify the degree to which the Stronger Families Program (Rodger et al., 2004) met parents' expectations and children's needs, by analysing parents' satisfaction with this service. Little is known as to why early intervention programs may be experienced differently by different parents. Two mothers who demonstrated lower levels of satisfaction than other mothers in the Stronger Families Program were studied in detail to explore possible factors that might have affected their satisfaction. In particular, this study aimed to describe how child, parent and service delivery factors might have impacted on these two mothers' experiences of the Stronger Families Program (referred to hereafter as the Program).

\section{Materials and Methods}

This study formed part of a larger project investigating family-centred early intervention for children with autism (Rodger et al. 2004). Using detailed case studies we explored factors that may have affected mothers' overall satisfaction with the Program. An exploratory case study approach was appropriate as it allowed researchers to describe participants in real-life contexts and identify potential explanations for mothers' low levels of satisfaction (Yin, 1994).

\section{$\underline{\text { Participants }}$}

The participants were two mothers identified from 16 mother-child dyads, who had completed the Program. Generally, mothers reported a high level of satisfaction with the Program on various satisfaction measures. Using purposive sampling (Yin, 1994) two mothers were identified who were less satisfied with the Program based on their scores on the post-program parent evaluation interview and questionnaire. Three questions in the evaluation interview asked 
mothers to rate their satisfaction with the way their home facilitator listened and respected their needs, wishes and routines, and provided information, on a scale of 1 to 5 (1: 'not satisfied' to 5: 'very satisfied'). Scores of 4 or less demonstrated lower satisfaction based on the finding that all other mothers rated 5 on all questions. Participants completed written project evaluations and identified their levels of agreement with statements including 'I am satisfied with the program to date', 'I feel the information provided was relevant to my needs' and 'Information provided has changed my understanding of ASD'. Ratings were from 1 ('strongly agree') to 5 ('strongly disagree'). Scores of 3 or greater indicated a degree of dissatisfaction. From these measures the two less satisfied mothers were identified.

Through this Program parents attended a two-day information and education workshop, followed by 10 one hour sessions of home-based early intervention. This focussed on mother identified goals. The strategies and techniques used during home facilitation were based on social-pragmatic approaches to early intervention for children with autism (Braithwaite, 2003).

\section{Instruments}

Several measures were used to investigate factors that may have contributed to mothers' satisfaction with the Program. These included child, parent and service measures.

Child Measures. A baseline assessment of children's adaptive functioning and maladaptive behaviour was determined using the Scales of Independent Behaviour - Revised (SIB-R) (Bruininks et al. 1996). The SIB-R provides a measure of adaptive functioning and gives an indication of the level of independence or amount of support an individual may need to meet their day to day needs. The maladaptive behaviour subscale measured the presence of difficult behaviours. 
The Communication and Symbolic Behaviour Scales Developmental Profile (CSBS-DP)

(Wetherby \& Prizant, 2002) assessed children's communication and symbolic behaviour. Children were videorecorded performing various standardised tasks for 30 minutes. Mothers were also asked to rate the child's communication and symbolic behaviour based on their knowledge of the child. These ratings were completed at baseline and post-intervention.

The Canadian Occupational Performance Measure COPM) (Law et al., 1998) was modified and used to assess performance and satisfaction with child's performance level on goals prior to and following the Program. Mothers were guided to identify their child's difficulties with communication/ behaviour, play/ leisure, and self-care (eating, toileting, bathing, grooming and hygiene). Mothers formulated between four and six child goals. They rated these (on a scale of 1 to 10) in terms of their child's goal performance and their satisfaction with this performance, at baseline and post-intervention.

Parent Measures. The Parent Sense of Competence (PSOC) (Johnston \& Mash, 1989) questionnaire was completed at baseline to describe mothers' self-esteem and feelings of competency in mothering their child with ASD. This tool assessed mothers' perceptions of satisfaction and efficacy in providing an overall indicator of parenting competence. The Parenting Stress Index (PSI) (Abidin, 1995) assessed mothers' total levels of stress, which comprised stress pertaining to their child and other parenting factors, which was measured at baseline. Service Measures. Mothers completed several questionnaires to indicate their perceptions of, and satisfaction with, various aspects of the Program. Firstly, the Measure of Processes of Care (MPOC) (King et al. 1995) required them to evaluate the care they received 
with regards to its degree of family-centredness, post-program. The results of three sub-domains are reported (Coordinated and Comprehensive Care, Partnership and Enabling, and Respectful and Supportive Care). The other two sub-domains related to the provision of general and specific information. These latter two domains were less relevant to the development of partnerships with professionals than the three chosen, which focus more on relationship parameters that are thought to be particularly influential in determining satisfaction with the Program (King et al. 1995; McWilliam et al. 1998).

Secondly, mothers completed a purpose-designed questionnaire at baseline, after an initial two-day workshop, and post-program. Questions considered how mothers' knowledge of ASD changed following the Program, and mothers' satisfaction with the intervention and how well it met their needs (the questionnaire is available from the first author).

Thirdly, a researcher independent of the study conducted a semi-structured interview by telephone with Program participants. As part of the interview mothers were asked to rate the respect received from their facilitator, information provided and how well they felt the facilitator listened, on scales of 1 ('not satisfied') to 5 ('very satisfied'). Facilitators were also interviewed independently and asked to highlight factors that may have affected their relationship with families.

\section{$\underline{\text { Procedure }}$}

Children and mothers completed the aforementioned pre- and post-intervention measures. The data collected allowed triangulation (Yin, 1994) by gathering information regarding multiple sources of evidence (i.e., about child outcomes, the mothers, and mechanisms of the service 
delivery) using standardised measures, interviews, as well as purpose designed questionnaires. Pseudonyms are used for purposes of anonymity throughout this paper

\section{Case Study One - Carly}

Carly and her husband attended the Program with their 3 year old son, who was diagnosed by a paediatrician with autism (and met Modified Checklist for Autism in Toddlers M-CHAT criteria for autism) (Robins, Fein, Barton \& Green, 2001) during the program. The parents lived together, and their household income was above the Australian average. The father was an artist and Carly was a home maintainer and did not work outside the home. In terms of parent level of education, Carly had completed a diploma and the father an undergraduate degree. The family reported that their son received a total of $14 \frac{1 / 4}{4}$ hours of therapy per week from a number of sources (outside the Program). He was the eldest of two children and obtained a standard score of 21 on the SIB-R, which represents limited to very limited skill level, indicating a need for pervasive support as age level tasks will be difficult to very difficult. He also scored -25 on the Maladaptive Behavior Scale of the SIB-R, which falls within the moderately serious range (Bruininks et al. 1996). Prior to participation in the Program, his standard score on the CSBS Behavior Sample was 94, and post intervention it fell to 80. The parent goals addressed during the Program included spontaneously initiating requests, responding to yes/no choices, playing alongside brother, reacting calmly to mess/spills and reducing self stimulation.

\section{Case Study Two - Diana}

Diana had a 3 year old girl with ASD diagnosed by her paediatrician (and meeting MCHAT criteria for autism) (Robins et al., 2001) who was the younger of two children. Diana and her husband lived together with a household income that was above the Australian average. 
Diana completed high school and was employed as a part-time administration assistant. Her husband completed a diploma and was an electrical engineering technical officer. Diana's daughter received $1 / 2$ an hour of therapy each week (in addition to the Program). She obtained a standard score of 79 on the SIB-R which represents limited to age appropriate skill level indicating a need for extensive support, as some age level tasks will be difficult. She also scored 22 on the Maladaptive Behavior Scale of the SIB-R, falling within the moderately serious range (Bruininks et al. 1996). Prior to participation in the Program, her standard score on the CSBS Behavior Sample was 126, and post intervention it increased to 133. The parent goals addressed included compliance with parent requests, independent play on own, tolerating sitting on toilet and regular nappy changes, coming calmly to dinner table and sitting (tolerating non preferred food item on plate).

\section{Results}

Figure 1 shows that overall satisfaction with the Program was lower for Carly and Diana than the rest of the mothers $(n=14)$. Carly's satisfaction was lower for information provision and facilitator listening, but similar to the group for facilitator respect. For Diana, all three questions demonstrate much lower satisfaction than the group mean for the other 14 mothers. Inspection of Figure 2 illustrates Carly and Diana's lower satisfaction levels on three post-program questions in the purpose-designed questionnaire. Their reported satisfaction was well below the group mean for the other 14 mothers.

[Insert Figure 1 and 2] 
Figure 3 displays mothers' mean ratings of their child's performance on various goals, and their satisfaction with this performance. While Carly and Diana reported greater satisfaction with goal performance after intervention, the amount of improvement seemed modest when compared to other families in the Program.

\section{[Insert Figure 3]}

Table 1 presents data from the Parent Stress Index (PSI) and Parenting Sense of Competence (PSOC) prior to the Program. Both Carly and Diana reported elevated levels of stress ranging between 95 to $99 \%$ ile. For Carly, this was particularly so in the parent factor domain whereas Diana's reported stress was relatively high in both the child and parent domains. Both Carly's and Diana's PSI scores were at the $99^{\text {th }}$ percentile for the child domain and both were above the $95^{\text {th }} \%$ ile for the parent domain indicating very high parenting stress. Carly's results on all of the PSOC subscales were comparable to other mothers in the Program. Her satisfaction scores were in the lower part of the normal range and efficacy comparable to the mean for typical children aged 4-6 years. Carly's total PSOC score was in the low average range. Diana's parenting satisfaction and total sense of competence scores were lower than average (based on means for typical children aged 4-6 years). Diana's satisfaction scores were low and efficacy scores within the low average range.

Figure 2 represents the mother's satisfaction with the program upon completion, based on the three statements - 'I am satisfied with the program to date', 'I feel the information provided was relevant to my needs'; and 'Information provided has changed my understanding of ASD'. Carly reported low satisfaction on all statements. She felt the Program met her family's needs "reasonably" well, however believed she did not learn anything new during the program. She 
commented that "when you have little to no free time and therapists.....are constantly intruding, they just add to the stress". Diana demonstrated the lowest satisfaction. Although she felt the workshop was "excellent", she stated "I don't feel I have gained very much from the facilitator visits". Diana mentioned she had higher expectations of the service and when asked what she had learnt, stated "not a great deal that I didn't already know”.

Figure 1 shows the evaluations of the mothers' relationships with their home facilitators. Carly responded similarly to the group with regards to respect from her facilitator. However, her results for information provided and listening by the facilitator appear considerably lower than the group mean. When asked whether the facilitator made her feel competent as a parent, Carly responded "No, not specifically - although she did not make me feel incompetent either". In regards to aspects she would change, Carly identified time schedules to be "less conflicting with the family". Some comments from Carly's home facilitator include "it was very difficult to make friends and build rapport with the mum" and the "parents seemed unable to commit to the program".

Figure 1 reveals that Diana was less satisfied than other mothers on all three components of the facilitator evaluation. When asked how her facilitator communicated with her, Diana replied that she was a "good listener" but "hesitant to discuss (issues)". She felt the facilitator used a "text book approach". Diana had mixed feelings of competency and reflected that her facilitator did not give her much positive feedback and “never really said I'm doing a good job”. She felt that her facilitator focused too much on her child and would have liked "more caring questions" from the facilitator. When interviewed, the facilitator mentioned she was "not entirely" able to support the family adequately as she "didn't realise how stressed (the) mother 
was as (she) seems in control". She believed that she may have "pushed too much at first until (she) realised this".

Figure 4 displays how client-centred the two mothers believed the Program was, based on three MPOC sub-domains. Partnership and Enabling (EP) reflects parent involvement, especially in decision-making; Coordinated and Comprehensive Care (CC) measures the holistic nature of the care and whether it is continuous and consistent over time, settings and facilitators; and Respectful and Supportive Care (RS) measures parents' perceptions of being treated with respect as individuals, equals and experts (King et al. 1995). Most families in the Program responded with ratings of 6 and 7 for these domains on a 7 point scale. The ratings for Carly and Diana were between 3 and 5 .

[Insert Figure 4]

\section{Discussion}

King et al. (2001) reported that satisfaction with services should be considered as a "multidimensional construct" as there are likely to be many contributing factors. Carly and Diana's children differed in their adaptive functioning and they had varying perceptions and experiences of their own parenting and the in-home facilitation that could have contributed to their satisfaction levels.

It is possible that Carly's satisfaction with the Program was influenced by her child's level of adaptive functioning. Carly's child obtained low scores on the SIB-R. It has been reported that children with more complex needs tend to receive services from more sources, 
which has been associated with lower parental satisfaction with those services (King et al. 2001). Carly's child received $14 \frac{1 / 4}{4}$ hours per week of intervention from a range of sources outside of the Program. Furthermore, this child's communication and symbolic behaviour did not improve following participation in the Program. Carly may have expected improvements in her child's communication and symbolic behaviour as a result of the intervention and the lack of improvement may have contributed to her dissatisfaction with the Program.

Over the course of intervention, Carly's son did show improvements in goal performance, but the increase was small. Carly's satisfaction with goal performance post-intervention remained low (3.2 out of 10). This may have translated into lower satisfaction with the service as she may have perceived less success with the Program in influencing her child's progress.

Carly and Diana both reported elevated stress levels while Diana also reported a somewhat lowered sense of parenting competence. It is well documented that parents (particularly, mothers) of children with disabilities experience greater levels of parenting stress than parents of typically developing children (e.g. Becker-Cottrill et al. 2003; Milgram \& Atzil, 1988; Olsson \& Hwang, 2002; Wolf et al. 1989). Possible links between parenting stress, sense of competence, and satisfaction with intervention services warrants further consideration and research. Previous research has suggested that coping strategies are critical for families to enable them to manage stress (Turnbull \& Turnbull, 1986), but that parents of children with ASD generally display fewer such strategies (Sivberg, 2002). This may affect the ability of parents to establish positive partnerships with professionals and influence satisfaction levels with services received. There is some support for this from the MPOC and interview data that indicated Carly and Diana were somewhat dissatisfied with their home facilitators. 
At interview, for example, Carly's home facilitator commented that it was hard to build rapport with her and she felt Carly was unable to commit to the program. Carly's MPOC results also indicated some dissatisfaction with her relationship and rapport with her facilitator. She reported that her facilitator only made her feel competent "sometimes" and she did not feel that the facilitator understood the demands of parenting her child. Interestingly, Carly did state during her interview that she was treated with respect and as a partner in the relationship and that there were no communication problems.

Diana reported a lower level of satisfaction with facilitator respect than all other participants in the Program. Her facilitator identified that the timing of the intervention was not optimal and initial rapport-building was hindered due to Diana's ill health. Diana commented that she did not really feel valued nor receive much positive feedback, making her feel incompetent. Milgram and Atzil (1988) stated that "it is more important for the distressed coper to believe that he/she is appreciated and valued than to receive specific services" (p. 422). Hence early intervention facilitators need to support parents as well as the child.

Diana described her partnership with her facilitator as "hesitant" and stated that she would have liked more understanding from her facilitator about her family's problems. There is a need for professionals to understand parents' perspectives, even when they are different from their own, in order to develop successful partnerships (Hanna \& Rodger, 2002). Diana's MPOC rating of the degree to which her in-home facilitation was respectful and supportive, also indicated low satisfaction. She felt the facilitator treated her family as a "case" rather than as individuals and didn't help her feel competent as a parent. 
Carly and Diana were also dissatisfied with the amount and relevance of information provided by their facilitators. King et al. (1996) found information exchange to have the strongest association with satisfaction among interpersonal aspects of care. An important role for professionals is the provision of information about appropriate resources (McBride et al. 1993). It appears that Carly in particular did not receive the information she would have liked regarding other services for her child or the reasons underlying intervention techniques and decisions. As a result, she may have had less opportunity for informed decision-making regarding the treatment, equipment and services that she utilised for her son.

Diana's main concern with information provision was its lack of relevance for her family, as she commented that it was "text book" in approach. Individualising information for families recognises that families are different and unique (Rosenbaum et al. 1998). Service providers who are good listeners are better able to understand families' unique perspectives and tailor information appropriately. Listening empathically conveys interest, understanding (Turnbull \& Turnbull, 1986), validates parents' observations of their child (Rosenbaum et al. 1998), and develops mutual respect (Bailey, 1987). Results showed that Carly in particular was less satisfied with her facilitator's listening than the rest of the group, which may have contributed to her decreased satisfaction.

\section{Conclusion}

In trying to understand the many factors that may contribute to parent satisfaction with intervention services, much can be learnt from Carly and Diana. However, this paper has focussed only on two mothers with lower levels of satisfaction hence care should be taken in generalising the results. In particular, the participants may not be representative due to their 
socioeconomic and educational demographics. Further research involving larger, more representative samples will be able to shed more light on the factors that affect parent satisfaction with early intervention programs. Further research could also investigate correlations between various child, parent, service factors, and parent satisfaction. There is also a role for in-depth qualitative interviews in further understanding parents' experiences of services for their children.

These results support the notion that parental satisfaction with early intervention is influenced by numerous factors, which can only be understood by evaluating child, parent and service factors, using multiple data sources. This has important implications for service providers and planners to consider satisfaction as a multidimensional concept that is influenced by many elements in addition to service factors (King et al. 2001). 


\section{References}

Abidin, R. R. (1995) Parenting Stress Index: Professional Manual ( $3^{\text {rd }}$ Ed). Psychological Assessment Resources, Inc., Odessa.

Bailey, D. B. (1987) Collaborative goal-setting with families: Resolving differences in values and priorities for service. Topics in Early Childhood Special Education 7, 59-71.

Becker-Cottrill, B., McFarland, J. \& Anderson, V. (2003) A model of positive behavioural support for individuals with autism and their families: The family focus process. Focus on Autism and Other Developmental Disabilities 18, 113-123.

Braithwaite, M. (2003) Social-pragmatic intervention with young children with autism and their caregivers: An investigation. Unpublished doctoral thesis. University of Queensland, Brisbane.

Bruininks, R. H., Woodcock, R. W., Weatherman, R. F. \& Hill, B. K. (1996) SIB-R: Scales of Independent Behaviour-Revised-Comprehensive Manual. The Riverside Publishing Company, Chicago.

Caro, P. \& Derevensky, J. L. (1991) Family-focused intervention model: Implementation and research findings. Topics in Early Childhood Special Education 11, 66-80.

De Geeter, K. I., Poppes, P. \& Vlaskamp, C. (2002) Parents as experts: The position of parents of children with profound multiple disabilities. Child: Care, Health \& Development 28, 443 453.

Fine, M. J. \& Gardner, A. (1994) Collaborative consultation with families of children with special needs: Why bother? Journal of Educational and Psychological Consultation 5, 283308.

Hanna, K. \& Rodger, S. (2002) Towards family-centred practice in paediatric occupational therapy: A review of the literature on parent-therapist collaboration. Australian Occupational Therapy Journal 49, 14-24.

Hwang, B. \& Hughes, C. (2000) The effects of social interactive training on early communicative skills of children with autism. Journal of Autism and Developmental Disorders 30, 331343.

Iverson, M. D., Poulin Shimmel, J., Ciacera, S. L. \& Prabhakar, M. (2003) Creating a familycentered approach to early intervention services: Perceptions of parents and professionals. Pediatric Physical Therapy 15, 23-31.

Johnson, C. (2000) What do families need? Journal of Positive Behaviour Interventions 2, 115117. 
Johnston, C. \& Mash, E. J. (1989) A measure of parenting satisfaction and efficacy. Journal of Clinical Child Psychology 18, 167-175.

King, G., Cathers, T., King, S. \& Rosenbaum, P. (2001) Major elements of parents' satisfaction and dissatisfaction with paediatric rehabilitation services. Children's Health Care 30, 111134.

King, G., King, S. \& Rosenbaum, P. (1996) Interpersonal aspects of care-giving and client outcomes: A review of the literature. Ambulatory Child Health 2, 151-160.

King, G., Law, M., King, S. \& Rosenbaum, P. (1998) Parents' and service providers' perceptions of the family-centredness of children's rehabilitation services. Physical \& Occupational Therapy in Paediatrics 18, 21-40.

King, S., Rosenbaum, P. \& King, G. (1995) The Measure of Processes of Care: A means to assess family-centred behaviours of health care providers. Neurodevelopmental Clinical Research Unit, Ontario.

Lanners, R. \& Mombaerts, D. (2000) Evaluation of parents' satisfaction with early intervention services within and among European countries: Construction and application of a new parent satisfaction scale. Infants and Young Children 12, 61-70.

Law, M., Baptiste, S., Carswell, A., McColl, M., Polatajko, H., \& Pollock, N. (1998). Canadian Occupational Performance Measure Manual ( $3^{\text {rd }}$ Ed.). Ottawa: CAOT Publications

Law, M., Hanna, S., King, G., Hurley, P., King, S., Kertoy, M. \& Rosenbaum, P. (2003) Factors affecting family-centred service delivery for children with disabilities. Child: Care, Health \& Development 29, 357-366.

Mahoney, G., Boyce, G., Fewell, R. R., Spiker, D. \& Wheeden, C. A. (1998). The relationship of parent-child interaction to the effectiveness of early intervention services for at-risk children and children with disabilities. Topics in Early Childhood Special Education 18, 517.

Marfo, K., Browne, N., Gallant, D., Smyth, R. \& Corbett, A. (1991) Issues in early intervention: A critical appraisal of applied research. Journal of Pediatric Psychology 10, 305-324.

McBride, S. L., Brotherson, M. J., Joanning, H., Whiddon, D. \& Demmitt, A. (1993) Implementation of family-centred services: Perceptions of families and professionals. Journal of Early Intervention 17, 414-430.

McNaughton, D. (1994) Measuring parent satisfaction with early childhood intervention programs: current practice, problems, and future perspectives. Topics in Early Childhood Special Education 14, 26-48.

McWilliam, R. A., Tocci, L. \& Harbin, G. L. (1998) Family-centred services: Service providers' discourse and behaviour. Topics in Early Childhood Special Education 18, 206-221. 
Milgram, N. A. \& Atzil, M. (1988) Parenting stress in raising autistic children. Journal of Autism and Developmental Disorders 18, 415-425.

Miller, L. J. \& Hanft, B. E. (1998) Building positive alliances: Partnerships with families as the cornerstone of developmental assessment. Infants and Young Children 11, 49-60.

Minke, K. M. \& Scott, M. M. (1995) Parent-professional relationships in early intervention: A qualitative investigation. Topics in Early Childhood Special Education 15, 335-352.

Olsson, M. B. \& Hwang, C. P. (2002) Sense of coherence in parents of children with different developmental disabilities. Journal of Intellectual Disability Research 46, 548-559.

Ozonoff, S. \& Cathcart, K. (1998) Effectiveness of a home program intervention for young children with autism. Journal of Autism and Developmental Disorders 28, 25-32.

Richards, S. B., Taylor, R. L., Ramasamy, R. \& Richards, R. Y. (1999) Analysis of single system design. In: Single Subject Research: Applications in Educational and Clinical Settings, pp. 428-441, Singular Publishing Group, Inc., San Diego.

Rodger, S., Braithwaite, M. \& Keen, D. (2004) 'Early Intervention for Children with Autism: Parental Priorities', Australian Journal of Early Childhood 29(3):34-41.

Rogers, S. J. (1998) Empirically supported comprehensive treatments for young children with autism. Journal of Clinical Child Psychology 27, 168-179.

Rosenbaum, P., King, S., Law, M., King, G. \& Evans, J. (1998) Family-centred service: A conceptual framework and research review. Physical \& Occupational Therapy in Pediatrics 18, $1-20$.

Robins, D. L., Fein, D., Barton, M. L., \& Green, A. (2001). The Modified Checklist for Autism in Toddlers: An Initial Study Investigating the Early Detection of Autism and Pervasive Developmental Disorders. Journal of Autism and Developmental Disorders, 31, 131-144.

Rosin, P. (1996) Parent and service provider partnerships in early intervention. In: Partnerships in Family-Centred Care: A Guide to Collaborative Early Intervention (Eds P. Rosin, A. D. Whitehead, L. I. Tuchman, G. S. Jesien, A. L. Begun \& L. Irwin), pp. 65-79. Paul H. Brookes Publishing Co., Inc, Sydney.

Sivberg, B. (2002) Family systems and coping behaviors: A comparison between parents of children with autistic spectrum disorders and parents with non-autistic children. Autism 6 , 397-409.

Sperry, L. A., Whaley, K. T., Shaw, E. \& Brame, K. (1999) Services for young children with autistic spectrum disorder: Voices of parents and providers. Infants and Young Children 11, 17-33. 
Turnbull, A. P. \& Turnbull, H. R. (1986) Parents, Professionals, and Exceptionality: a Special Partnership. Merrill Publishing Company, Ohio.

Upshur, C. C. (1991) Mothers' and fathers' ratings of the benefits of early intervention services. Journal of Early Intervention 15, 345-357.

Wetherby, A. M. \& Prizant, B. M. (2002) Communication \& Symbolic Behaviour Scales Developmental Profile. Paul H. Brookes, Baltimore.

Wing, L. Autistic spectrum disorders. British Medical Journal, 312, 327-328.

Wolf, L. C., Noh, S., Fisman, S. N. \& Speechley, M. (1989) Brief report: Psychological effects of parenting stress on parents of autistic children. Journal of Autism and Developmental Disorders 19, 157-166.

Yin, R. K. (1994) Case Study Research: Design and Methods ( $2^{\text {nd }}$ Ed). Sage Publications London. 


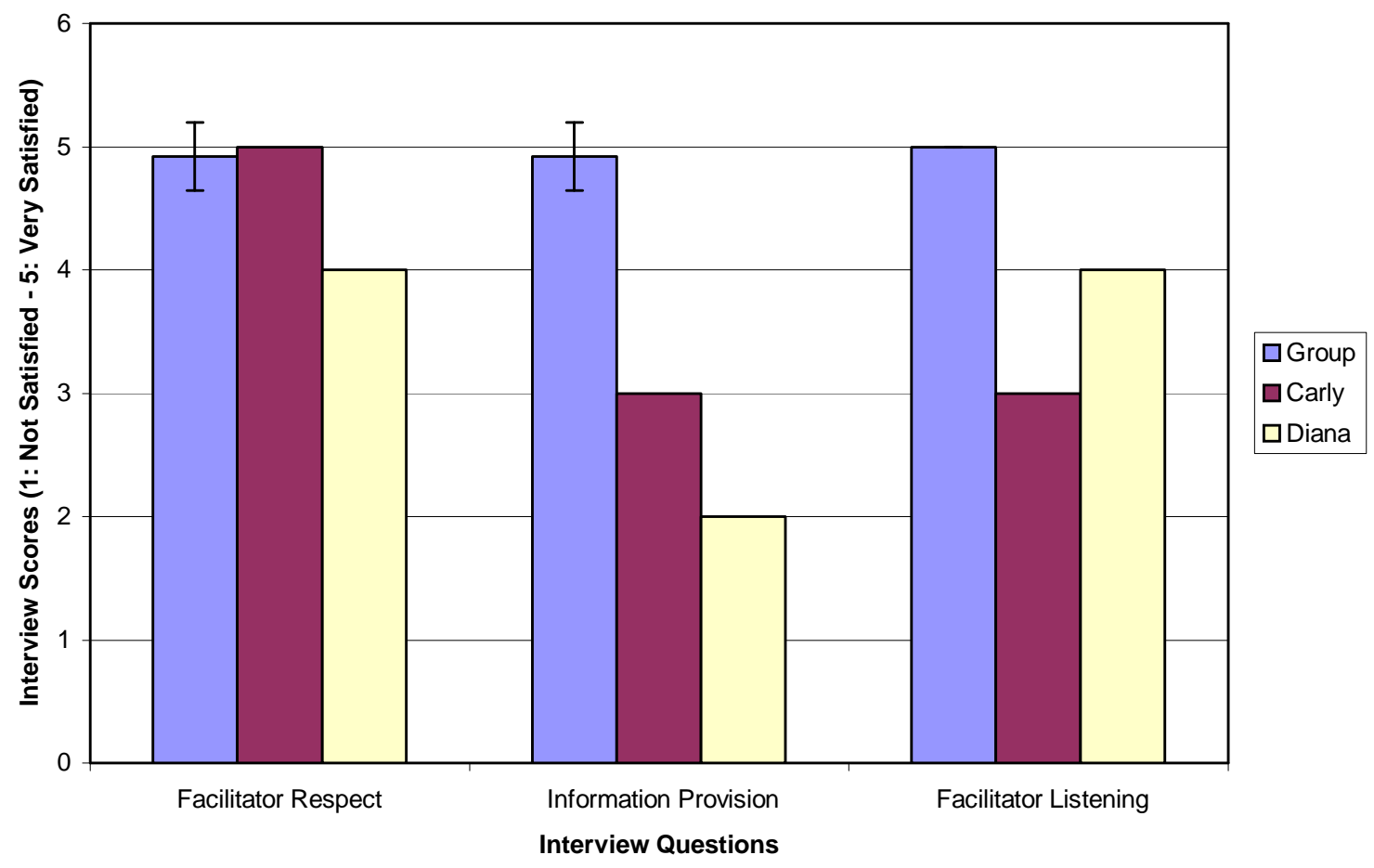

Figure 1. Mean post-program ratings (and standard deviations where appropriate) for group $(n=14)$ and case study mothers in response to interview questions about home facilitators. 


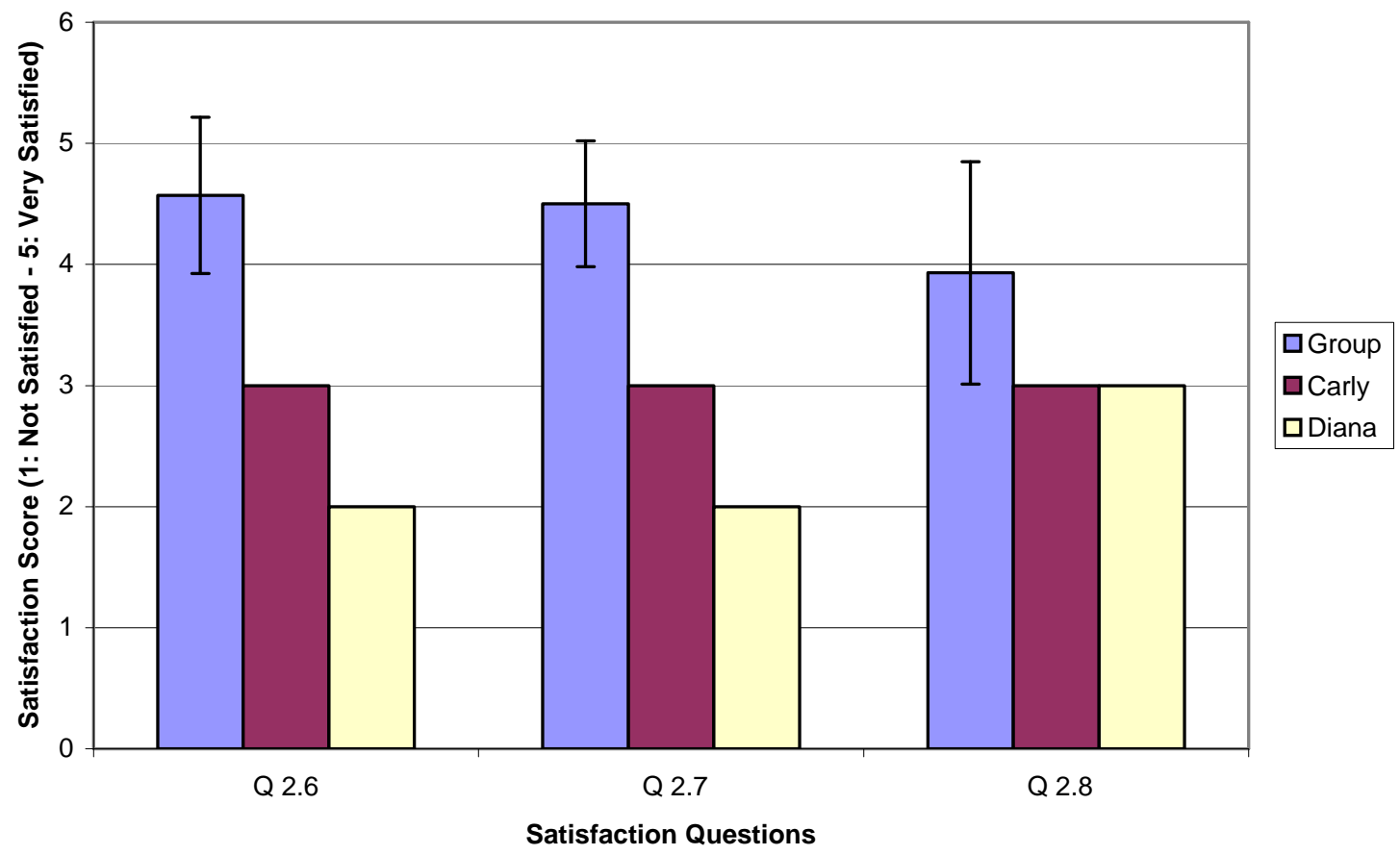

Figure 2. Mean post-program questionnaire ratings (and standard deviations) for group $(\mathrm{n}=14)$ and case study mothers.

Q 2.6 'I am satisfied with the program to date', Q 2.7 'I feel the information provided was relevant to my needs'; Q 2.8 'Information provided has changed my understanding of 
ASD'

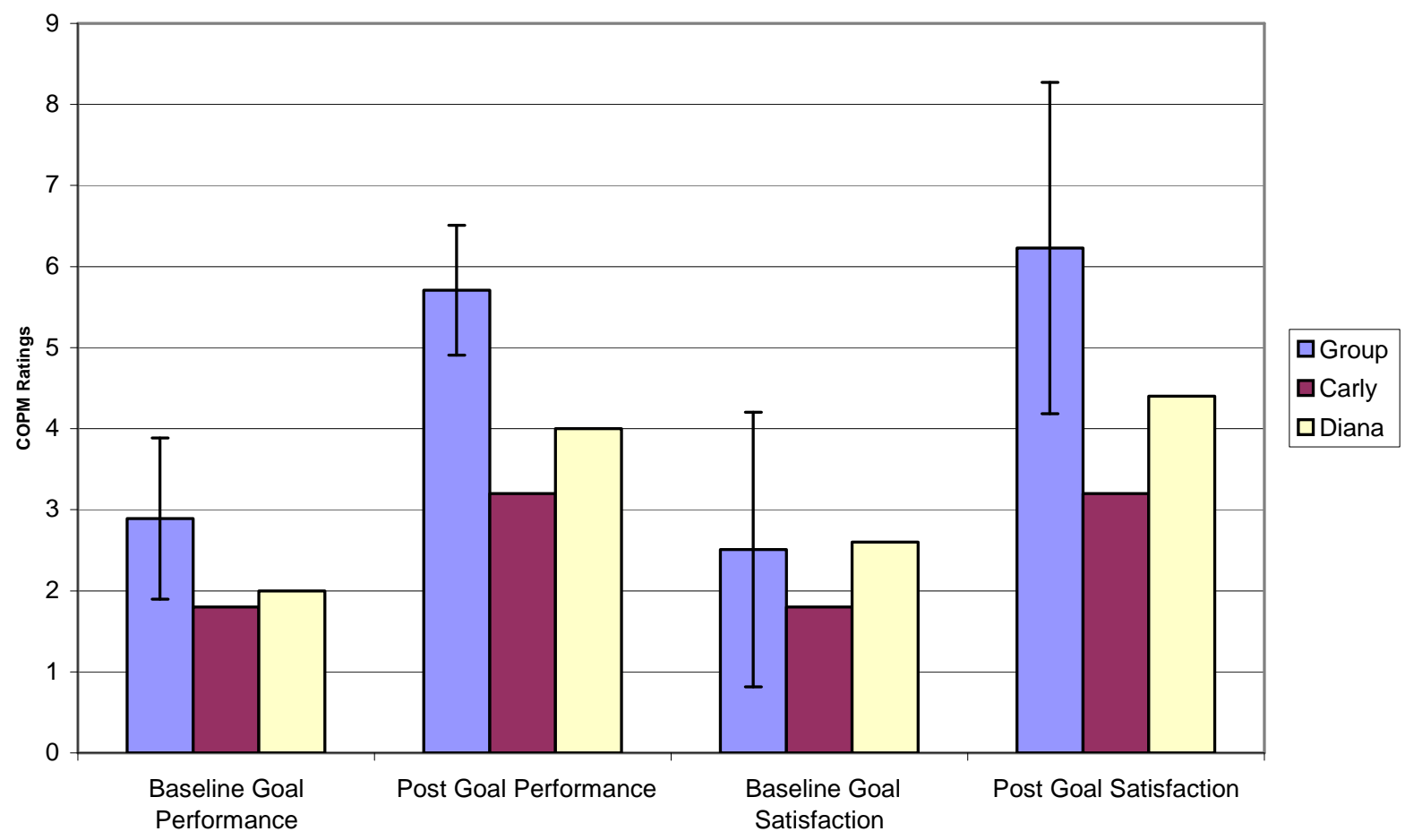

Figure 3. Mothers' ratings of child goal performance and satisfaction on the Canadian Occupational Performance Measure (COPM) for group (mean and standard deviation) and case study children. 


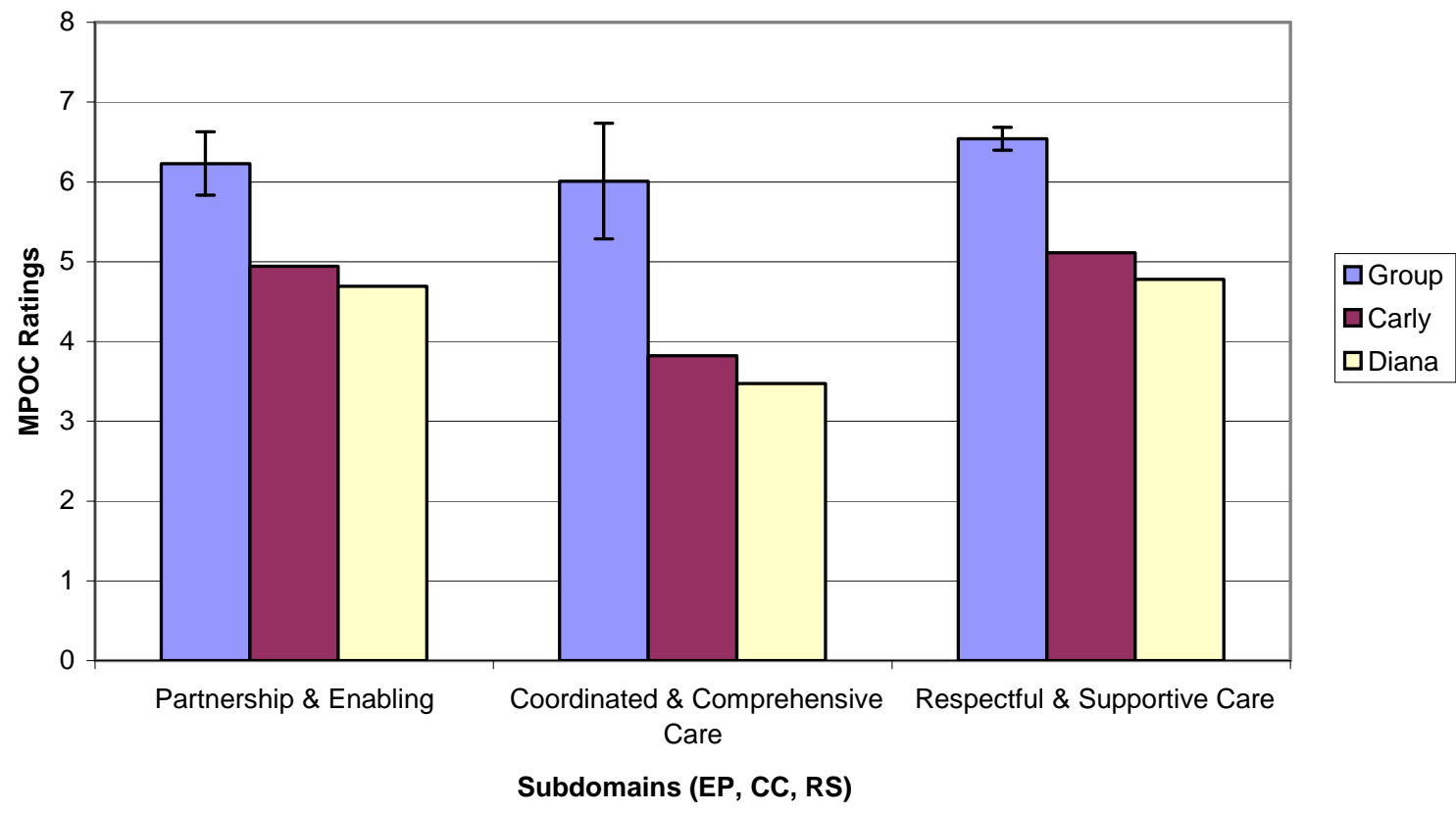

Figure 4. Measure of Processes of Care (MPOC) post-program for group (mean and standard deviation) and case study mothers. 


\section{Legend of Figures}

Figure 1. Mean post-program ratings (and standard deviations where appropriate) for group $(n=14)$ and case study mothers in response to interview questions about facilitators.

Figure 2. Mean post-program questionnaire ratings (and standard deviations) for group $(n=14)$ and case study mothers.

Figure 3. Mothers' ratings of child goal performance and satisfaction on the Modified Canadian Occupational Performance Measure (M-COPM) for group (mean and standard deviation) and case study children.

Figure 4. Measure of Processes of Care (MPOC) post-program for group (mean and standard deviation) and case study mothers. 
Table 1. Two Mothers' Parenting Stress (PSI) and Competence (PSOC) Scores at Baseline compared with Manual Means (SDs) and Ranges.

\begin{tabular}{|c|c|c|c|c|c|c|}
\hline & \multicolumn{3}{|c|}{ Carly's Scores at Baseline } & \multicolumn{3}{|c|}{ Diana's Scores at Baseline } \\
\hline & Child & Parent & Total & Child & Parent & Total \\
\hline $\begin{array}{l}\text { PSI Standard } \\
\text { Score } \\
\text { (mother's } \\
\text { stress ) }\end{array}$ & $\begin{array}{l}143 \\
\text { (99\%ile) }\end{array}$ & $\begin{array}{l}194 \\
\text { (99\%ile) }\end{array}$ & $\begin{array}{l}337 \\
(>99 \% \text { ile })\end{array}$ & $\begin{array}{l}155 \\
\text { (99\%ile) }\end{array}$ & $\begin{array}{l}164 \\
\text { (95\% ile) }\end{array}$ & $\begin{array}{l}319 \\
(98 \% \text { ile })\end{array}$ \\
\hline $\begin{array}{l}\text { PSI Manual } \\
3 \text { year olds }\end{array}$ & $\begin{array}{l}97 \\
(\mathrm{SD}=18)\end{array}$ & $\begin{array}{l}122 \\
(\mathrm{SD}-23)\end{array}$ & $\begin{array}{l}M=221 \\
(\mathrm{SD}=38)\end{array}$ & $\begin{array}{l}97 \\
(\mathrm{SD} \\
=18)\end{array}$ & $\begin{array}{l}122 \\
(\mathrm{SD}-23)\end{array}$ & $\begin{array}{l}\mathrm{M}=221 \\
(\mathrm{SD}=38)\end{array}$ \\
\hline & $\begin{array}{l}\text { Satisfactio } \\
\mathrm{n}\end{array}$ & Efficacy & Total & $\begin{array}{l}\text { Satisfact } \\
\text { ion }\end{array}$ & Efficacy & Total \\
\hline $\begin{array}{l}\text { PSOC } \\
\text { Standard } \\
\text { Score } \\
\text { (mother's } \\
\text { parenting } \\
\text { competence) }\end{array}$ & 34 & 25 & 59 & 27 & 23 & 50 \\
\hline $\begin{array}{l}\text { PSOC Mean } \\
{ }^{2}(\mathrm{SD}) \text { scores } \\
\text { and range for } \\
\text { mothers of } \\
\text { boys }\end{array}$ & $\begin{array}{l}37.40 \\
(6.60) \\
(31-44)\end{array}$ & $\begin{array}{l}25.52 \\
(5.29) \\
(20-31)\end{array}$ & $\begin{array}{l}63.00 \\
(9.74)(53- \\
73)\end{array}$ & $\begin{array}{l}38.76 \\
(5.87) \\
(33-45) \\
\text { PSOC } \\
\text { Mean } \\
\text { scores } \\
\text { for } \\
\text { mothers } \\
\text { of girls }\end{array}$ & $\begin{array}{l}25.08 \\
(5.97) \\
(19-31)\end{array}$ & $\begin{array}{l}63.83 \\
(9.92)(54- \\
74)\end{array}$ \\
\hline
\end{tabular}

From ${ }^{1}$ Abidin (1995) and ${ }^{2}$ Johnston and Mash (1989). 
